\title{
Evaluation of orthodontic mini-implant placement: a CBCT study
}

\author{
Shilpa Kalra*, Tulika Tripathi, Priyank Rai and Anup Kanase
}

\begin{abstract}
Background: Optimal positioning of orthodontic mini-implants is essential for a successful treatment with skeletal anchorage. This study aims to compare the accuracy of two-dimensional radiographs with a cone beam computed tomography (CBCT) for mini-implant placement.

Methods: An ideal site for mini-implant placement at the buccal interradicular space between the second premolar and the first molar was determined for 40 sites (in 13 patients aged 14 to 28 years) by using CBCT data. The mini-implant placement procedure was then divided into two groups. In CBCT group, mini-implants were placed at the sites determined from CBCT data. In RVG group, mini-implants were placed with the help of two-dimensional digital radiographs and a custom made guide. Postplacement $C B C T$ scans were obtained to determine the accuracy of the mini-implant placement. The results were statistically analyzed with a Mann-Whitney test.

Results: A statistically significant difference ( $p$ value $=0.02$ ) was observed between the two groups for deviation from an ideal height of placement of the mini-implants. Deviations in mesiodistal positioning and angular deviation showed a statistically non-significant difference. Three out of twenty mini-implants in the RVG group showed root contact in the mandibular arch that may be attributed to the narrower interradicular space and reduced accessibility in the mandibular posterior region.

Conclusions: Although CBCT provides an accurate three-dimensional visualization of the interradicular space, the two-dimensional intraoral radiograph of the interradicular area provides sufficient information for mini-implant placement. Considering the amount of radiation exposure and cost with the two techniques, it is recommended to use two-dimensional radiographs with a surgical guide for a routine mini-implant placement.
\end{abstract}

Keywords: CBCT; Digital RVG; Mini-implant

\section{Background}

The use of orthodontic mini-implants as an absolute anchorage device has seen a marked increase in orthodontic treatment $[1,2]$. Despite their advantages over the extraoral anchorage methods, mini-implants can occasionally loosen during treatment and eventually fail to provide firm anchorage [3-5]. A study showed that the rates of mini-implant failure vary between $11 \%$ and $30 \%$ [6].

The two major factors that clinicians should consider for mini-implant placement are safety and stability. Safety is related to avoiding root damage during implant placement in the interradicular space. Stability, especially initial stability, which plays a major role in preventing

\footnotetext{
* Correspondence: shilpa26kalra@gmail.com

Department of Orthodontics and Dentofacial Orthopaedics, Maulana Azad Institute of Dental Sciences, New Delhi 110002, India
}

premature loosening of mini-implants, is obtained by placing the mini-implants in the alveolar bone with sufficient quantity and quality $[3,7]$.

Fayed et al [8] suggested that the optimal sites for miniimplant placement are between the second premolar and first molar and between the first and second molars at the buccal aspect of the posterior region of both jaws. Successful placement of mini-implants at the desired site is critical for their incorporation into the clinical practice. Kim et al [9] presented a surgical guide system that used cone beam computed tomography (CBCT) images to replicate the dental models. Surgical guides for the proper positioning of orthodontic mini-implants were fabricated on the replicas and used for precise placement. Liu et al [10] introduced a CAD/CAM template with preoperative simulation for orthodontic miniscrew placement. Similarly, other authors

\section{穴}

(c) 2014 Kalra et al.; licensee Springer. This is an Open Access article distributed under the terms of the Creative Commons Attribution License (http://creativecommons.org/licenses/by/4.0), which permits unrestricted use, distribution, and reproduction in any medium, provided the original work is properly credited. 

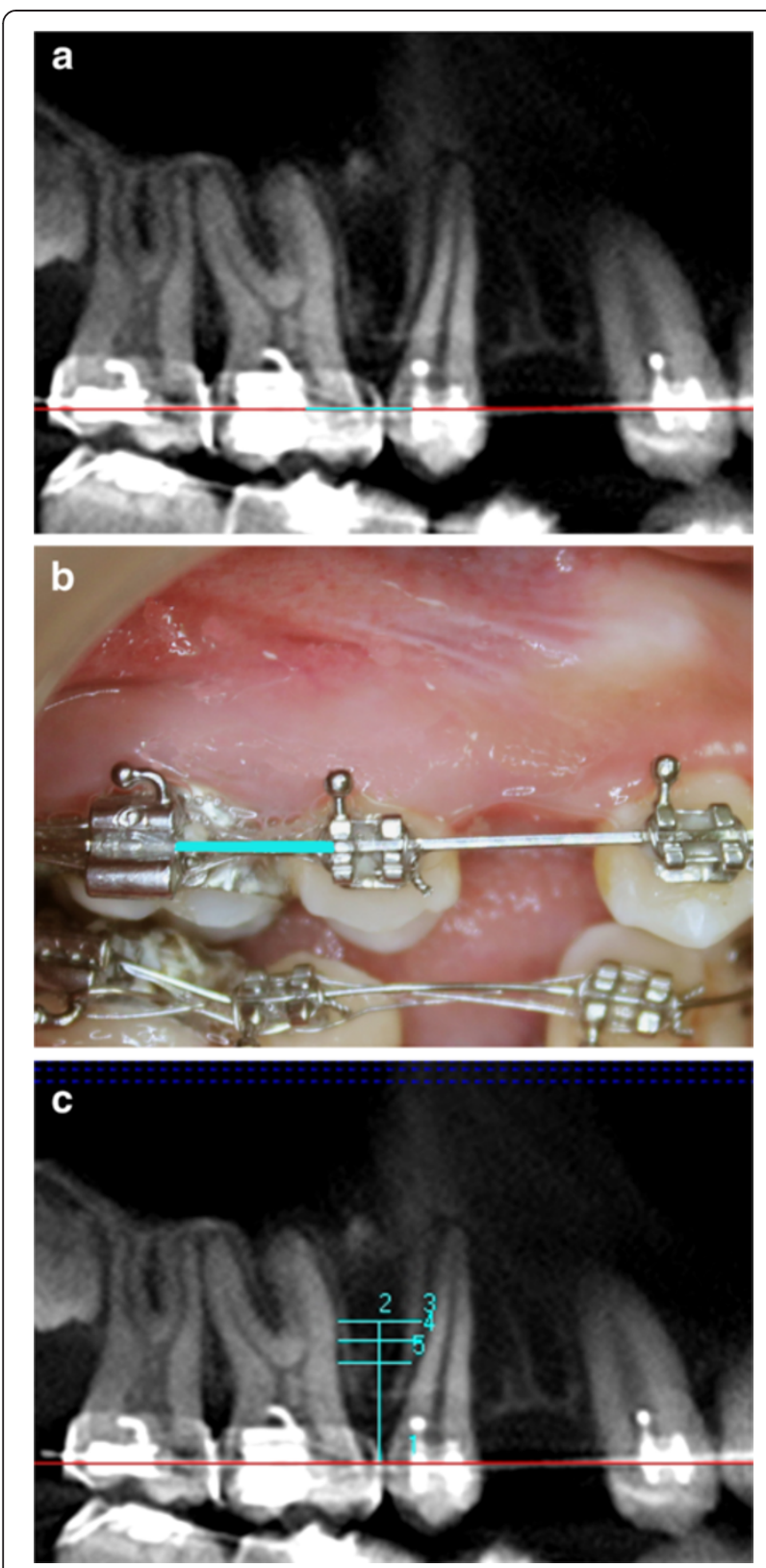

Figure 1 Orthodontic arch wire in second premolar and first molar region taken as standard reference for measurements. (a) Panorex View of CBCT image, (b) correlated clinically, and (c) various heights from the arch wire within the limits of mucogingival junction selected for bone measurements.

have reported the extensive use of three-dimensional planning with the help of surgical guides, stents, and templates for accurate mini-implant positioning [11,12]. Although CBCT provides additional diagnostic and therapeutic information, it exposes the patients to a higher level of radiations than the conventional radiographs [13-15]. Thus, there is a need to assess whether the use of such an expensive and laborious procedure is required or not.
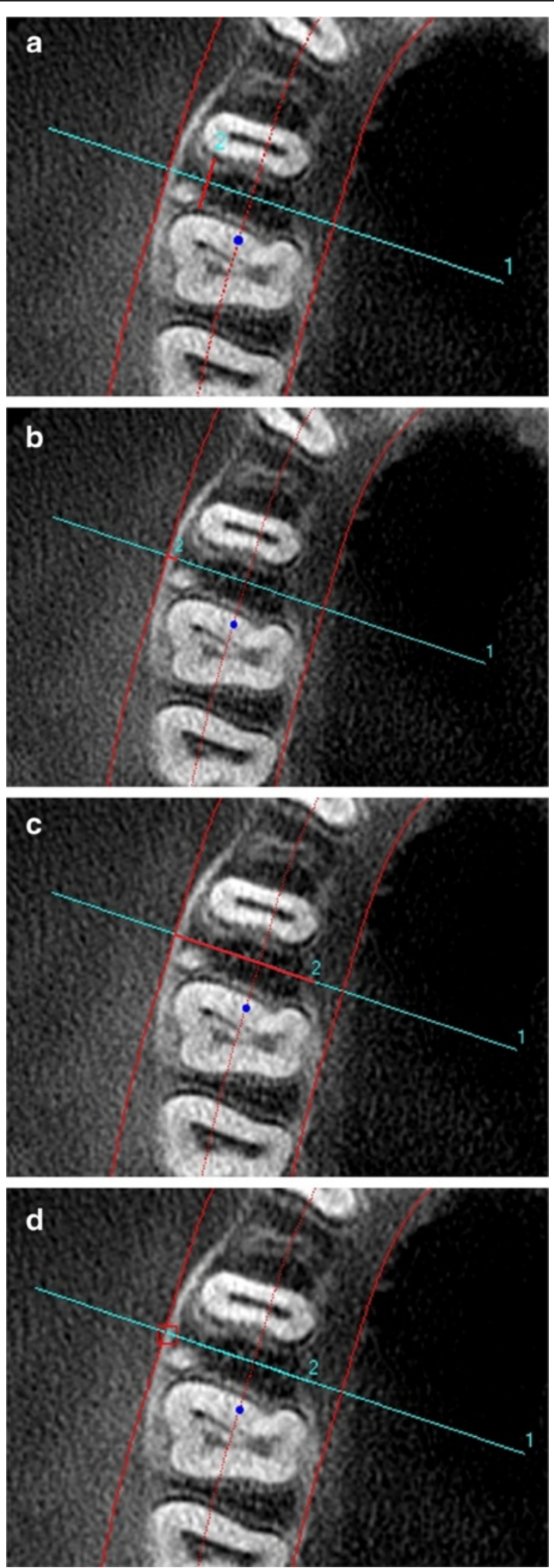

Figure 2 Bone measurements. (a) Mesiodistal distance, (b) buccal cortical bone thickness, (c) buccolingual thickness, and (d) bone density. 


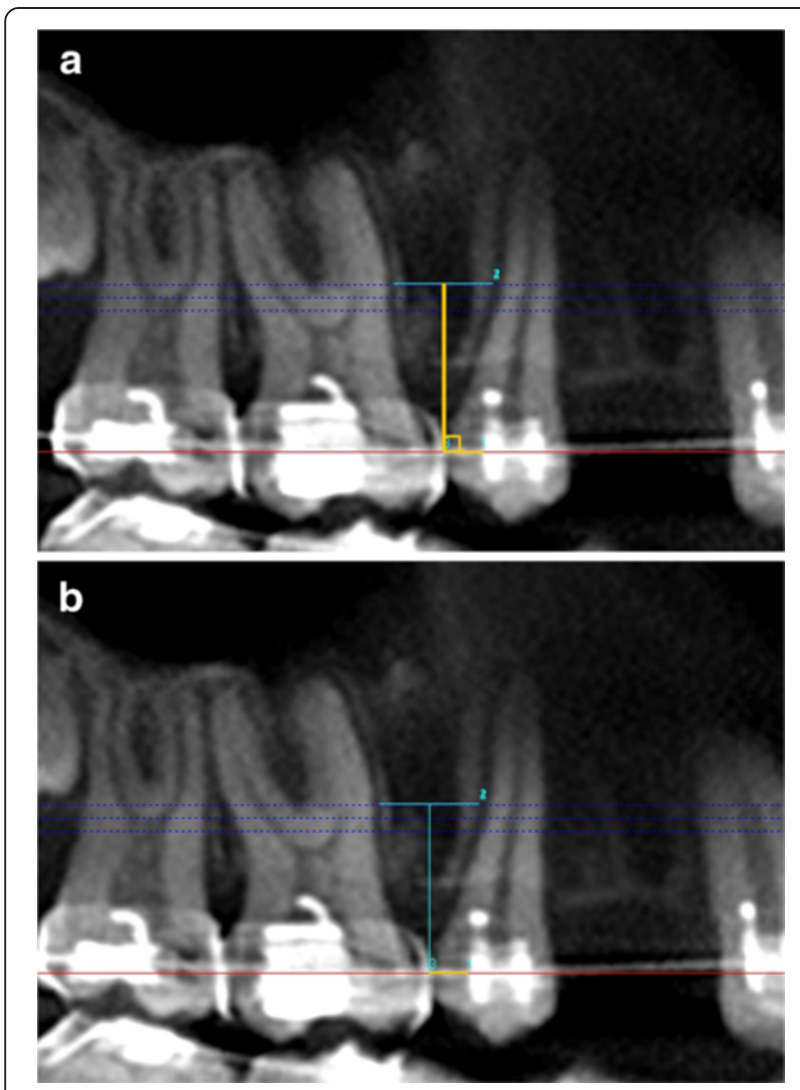

Figure 3 Determination of the point of entry of mini-implant by using CBCT data. (a) A perpendicular is dropped from ideal point of insertion of mini-implant to the arch wire. (b) Distance of point of intersection of perpendicular on the arch wire to distal end of second premolar bracket.

However, most clinicians routinely place mini-implants without $3 \mathrm{D}$ planning and use the two-dimensional radiographs for presurgical treatment planning. In an effort to minimize insertion errors, several innovative surgical guides have been used which help in avoiding root injury and subsequent patient discomfort [16-20].

Despite the extensive use of two-dimensional radiographs for mini-implant placement, little has been recorded in literature to determine their accuracy for site selection and position of mini-implants thereafter.

The present study was aimed at evaluating the accuracy of two-dimensional radiographs for site selection and orthodontic mini-implant placement.

\section{Methods}

The present study evaluated 40 mini-implant placement sites in 13 patients (10 females and 3 males) aged between 14 and 28 years from North Indian population group who reported for orthodontic treatment to the Department of Orthodontics, Maulana Azad Institute of Dental Sciences, Delhi. The included cases required the extraction of the upper and/or lower first premolars with high anchorage

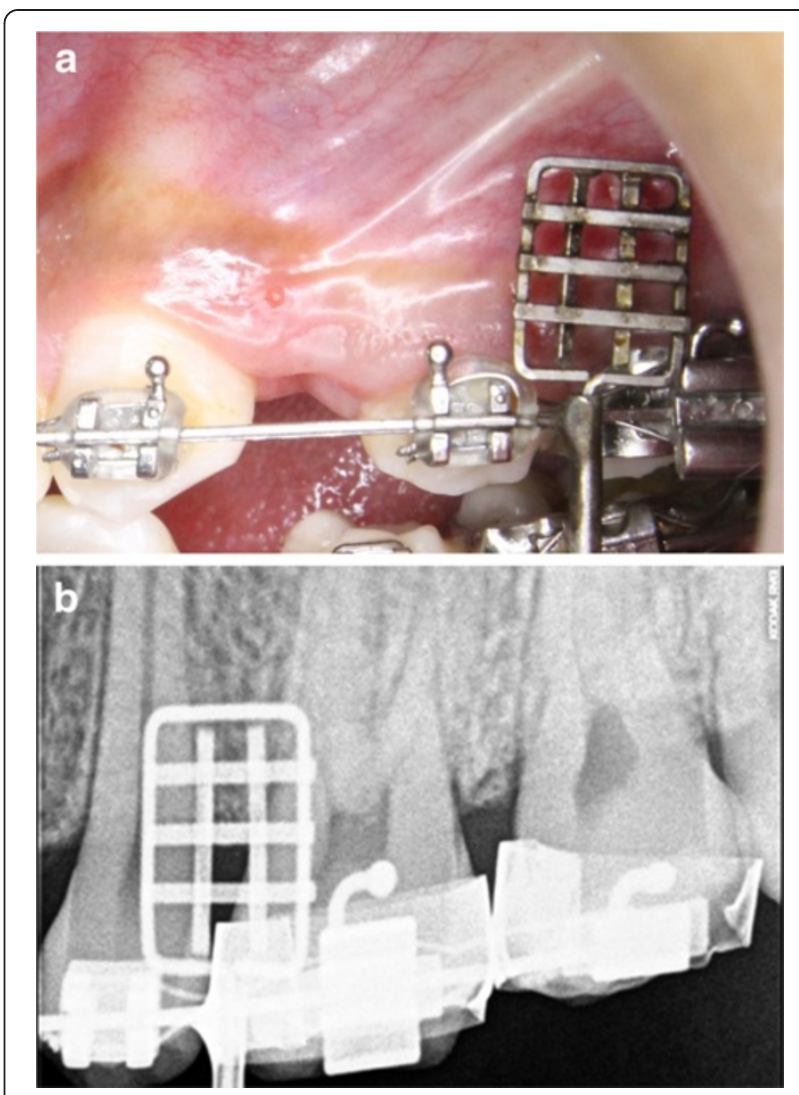

Figure $\mathbf{4}$ Custom made guide in second premolar and the first molar region. As seen (a) clinically and (b) radiographically.

consideration and were represented by eight class I bidentoalveolar protrusion patients, four class II division 1 malocclusion patients, and one class III surgical case. Twentyfour mini-implants $(1.5 \times 9 \mathrm{~mm}$ Infinitas mini-implant system, DB Orthodontics Limited, West Yorkshire, UK) were placed in the maxillae and sixteen in the mandible. The study was sanctioned by the Institutional Ethics Committee and informed consent was obtained from all the patients/

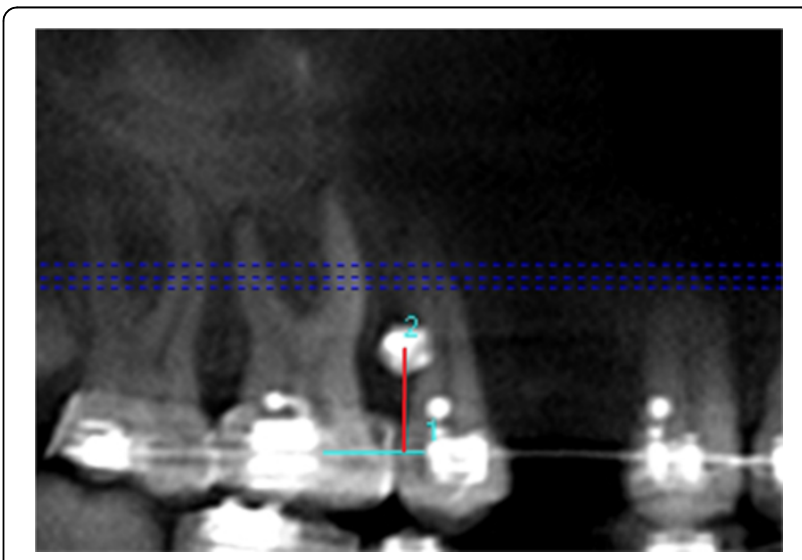

Figure 5 Height of mini-implant from arch wire. 
Figure 6 The post insertion measurements. (a) Deviation of the point of entry of the mini-implant $\left(D M_{E P}\right)$. (b) Deviation of the tip of mini-implant (DMT). (c) Angular deviation of path of mini-implant $\left(\mathrm{DM}_{\mathrm{A}}\right)$. (d) Root proximity to the mini-implant.

guardians of the patients. The patients who agreed to have CBCT scans prior to and after mini-implant placement were included in the study. Pre- and postplacement CBCT scans were taken at an interval of 3 months. Patients with mixed dentition, missing teeth, severe periodontitis, and systemic diseases contraindicating the procedure were excluded.

The study design was randomized block design in which the 40 sites (sample units) were first grouped as 20 pairs (left and right interradicular sites in the same arch in a patient as one pair). All the 20 pairs were then randomly allocated by using split mouth system into two groups such that mini-implant placement was guided by $\mathrm{CBCT}$ on one side and RVG (digital intraoral periapical radiograph) on the other side in all the patients.

All the patients were treated with a preadjusted edgewise appliance of MBT prescription $(0.022 \times 0.028$-in. slot $)$. A sequence of aligning wires was used for leveling and alignment until a $0.019 \times 0.025$-in. stainless steel arch wire could be passively engaged.

After initial leveling and alignment, CBCT scans ( iCAT Cone beam three-dimensional imaging system, Imaging Sciences, Hatfield, PA, USA) were performed for all the patients for the determination of the ideal site for miniimplant placement in the buccal interradicular space between the second premolar and the first molar in maxillary and/or mandibular arches (with arch wires in place). CBCT scan was taken with the dosimetry parameters of $120 \mathrm{kV}, 37.07 \mathrm{~mA}$, and $40 \mathrm{~s}$ scan time. Measurements were performed by an expert oral and maxillofacial radiologist using iCAT vision software for bone density assessment and linear measurements and Digimizer (Version 4.0, MedCalc Software, Ostend, Belgium) image analysis software for angular measurements.

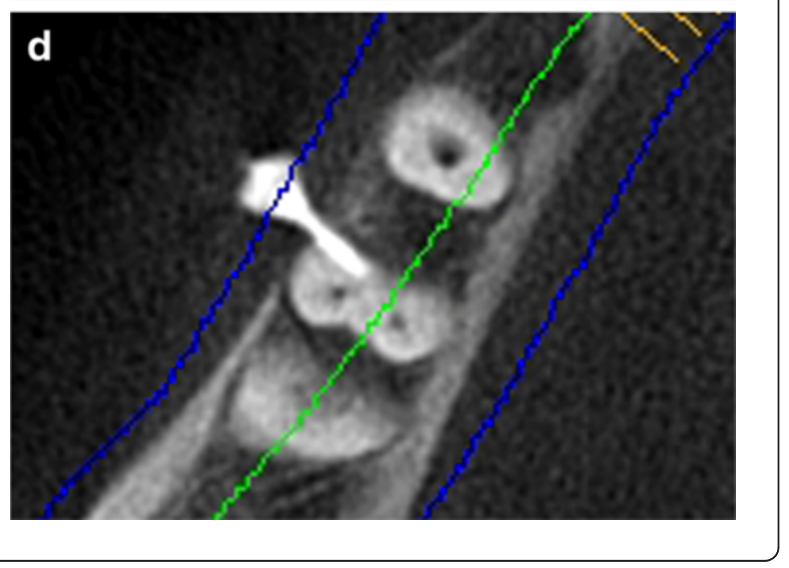

\section{Determination of ideal site for mini-implant placement}

Orthodontic arch wire in the second premolar and the first molar region was taken as a reference for all the measurements (Figure 1a,b). Four bone measurements namely mesiodistal distance, cortical bone thickness, buccolingual thickness, and bone density were obtained in the axial slice sections corresponding to the various heights from the arch wire within the limits of mucogingival junction (Figure 1c and Figure 2). The level of mucogingival junction in the second premolar and the first molar region was predetermined clinically, and its distance from the arch wire was also calculated. Based on the measurements performed by an oral radiologist, the vertical level with a maximum mesiodistal 


\section{CBCT GROUP}

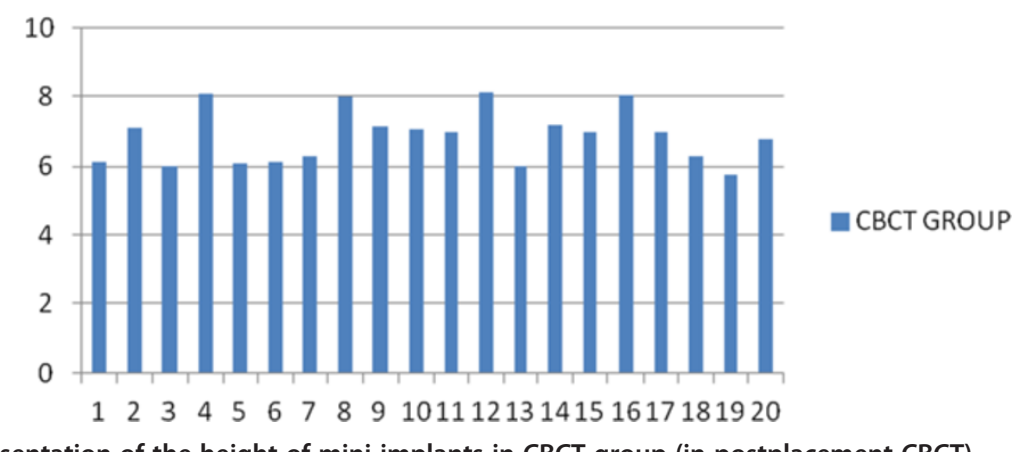

Figure 7 Graphical representation of the height of mini-implants in $\mathrm{CBCT}$ group (in postplacement CBCT).

interradicular distance with optimum buccal cortical plate thickness, bone density, and buccolingual thickness was considered to be the ideal height for mini-implant placement. Hence, ideal site for all the mini-implants were identified (center of the mesiodistal space at the determined ideal height).

However, this information was given to the operator only for CBCT-guided side during the mini-implant placement.

\section{CBCT group}

In the CBCT group, the ideal sites as determined in the CBCT images were correlated clinically for the correct mesiodistal positioning of mini-implants at the desired height.

\section{Determination of the point of entry of mini-implant clinically by using CBCT data}

1. A perpendicular was dropped from the ideal point of insertion of mini-implant to the arch wire (in CBCT image) (Figure 3a).
2. The distance of the point of intersection of the perpendicular on the arch wire to the distal end of the second premolar bracket was measured (in the CBCT image) (Figure 3b).

- This distance was used clinically to mark the mesiodistal positioning of the mini-implant on the CBCT-guided side.

3. The ideal height for the mini-implant placement was marked intraorally as determined in the CBCT image.

The operator was trained by the oral and maxillofacial radiologist for interpreting the $\mathrm{CBCT}$ measurements. Based on the measurements derived, the operator inserted the mini-implants at the identified sites under local anesthesia.

\section{Digital intraoral radiography/digital RVG group}

An intraoral periapical view of the second premolar and the first molar region with custom made guide [21] in place using digital RVG (Kodak RVG 5100, Marne-lavallée, France) was taken (Figure 4). The custom made guide consists of two parts: a grid and a grid holder.

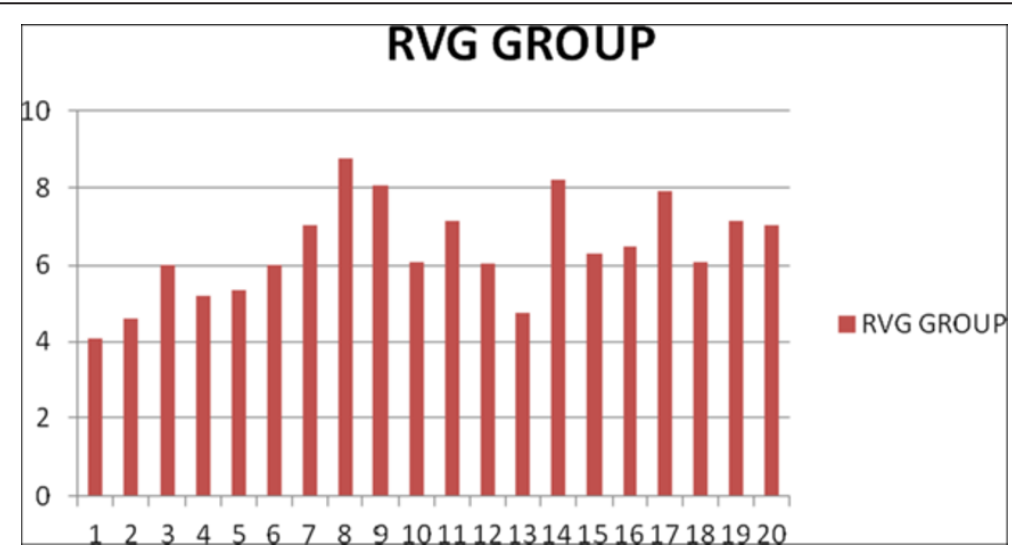

Figure 8 Graphical representation of the height of mini-implants in RVG group (in postplacement CBCT). 
Table 1 Comparison of mean deviation of mini-implants from ideal position between CBCT group and RVG group with level of significance

\begin{tabular}{lccc}
\hline Variable & $\begin{array}{l}\text { CBCT group } \\
(\boldsymbol{n}=\mathbf{2 0})\end{array}$ & $\begin{array}{l}\text { RVG group } \\
(\boldsymbol{n}=\mathbf{2 0})\end{array}$ & $\begin{array}{l}\text { Significance } \\
\text { ( } \boldsymbol{p} \text { value) }\end{array}$ \\
\hline Mean $\mathrm{DM}_{\mathrm{H}}$ (in mm) & 0.0985 & 0.565 & $0.02^{*}$ \\
Mean $\mathrm{DM}_{\mathrm{EP}}$ (in mm) & 0.391 & 0.651 & 0.143 \\
Mean $\mathrm{DM}_{\mathrm{T}}$ (in mm) & 0.586 & 1.038 & 0.204 \\
Mean $\mathrm{DM}_{\mathrm{A}}$ (in degrees) & 4.7 & 6.2 & 0.624 \\
\hline
\end{tabular}

*Significant difference in mean deviation of height of mini-implant $(p<0.05)$ $\mathrm{DM}_{\mathrm{H}}$, deviation of height of mini-implant; $\mathrm{DM}_{\mathrm{EP}}$, deviation of point of entry of mini-implant; $\mathrm{DM}_{\mathrm{T}}$, deviation of tip of mini-implant; $\mathrm{DM}_{\mathrm{A}}$, angular deviation of mini-implant from the ideal path.

This grid provided an option of nine cells and the area which seemed to be centered between the adjacent roots and at an optimal height was identified as the site for mini-implant placement. A bleeding point was created with the explorer through the guide. The guide was then removed and mini-implant was inserted at the identified site under local anesthesia.

All the mini-implants were inserted by a single operator.

\section{Postplacement $C B C T$}

After insertion of the mini-implants, another CBCT scan for comparative evaluation of the accuracy of the site selection and mini-implant placement between the two groups was performed by an expert oral and maxillofacial radiologist.

The following parameters were observed in the postplacement $\mathrm{CBCT}$.

1. Height of the mini-implant from the arch wire (Figure 5)

- Deviation of height of mini-implant $\left(\mathrm{DM}_{\mathrm{H}}\right)$ from the ideal height was determined.

2. Mesiodistal position of the mini-implant at the interradicular area

- The ideal path of insertion of the mini-implant is drawn on the axial slice view and following parameters were measured. i. Deviation of the point of entry of mini-implant $\left(\mathrm{DM}_{\mathrm{EP}}\right)$ (Figure 6a)

ii. Deviation of the tip of mini-implant $\left(\mathrm{DM}_{\mathrm{T}}\right)$ (Figure 6b)

iii. Angular deviation of the mini-implant $\left(\mathrm{DM}_{\mathrm{A}}\right)$ from the ideal path (Figure 6c)

3. Root contact of the mini-implant in the axial slice view (Figure 6d)

\section{Statistical analysis}

The means and standard deviations for $\mathrm{DM}_{\mathrm{H}}, \mathrm{DM}_{\mathrm{EP}}, \mathrm{DM}_{\mathrm{T}}$, and $\mathrm{DM}_{\mathrm{A}}$ were calculated for the mini-implants placed in both groups. The data was tested for normality and it showed a non-normal distribution. Hence, the comparison of the means of $\mathrm{DM}_{\mathrm{H}}, \mathrm{DM}_{\mathrm{EP}}, \mathrm{DM}_{\mathrm{T}}$, and $\mathrm{DM}_{\mathrm{A}}$ between the groups and within each group was done by independent samples Mann-Whitney $U$ test (non-parametric test) with a $p$ value of less than 0.05 . Since the aim of the study was to compare between the two groups, only the absolute values without '+' or '-' signs were considered.

\section{Results}

The heights at which mini-implants were placed in the CBCT group and RVG group are graphically represented in Figures 7 and 8, respectively, with an average height of mini-implants being $6.85 \mathrm{~mm}$ in CBCT group and $6.40 \mathrm{~mm}$ in RVG group. Mean values for $\mathrm{DM}_{\mathrm{H}}, \mathrm{DM}_{\mathrm{EP}}$, $\mathrm{DM}_{\mathrm{T}}$, and $\mathrm{DM}_{\mathrm{A}}$ for the CBCT group and RVG group along with the comparison of these parameters are tabulated in Table 1 . Statistically significant difference ( $p$ value $=0.02)$ was observed between the two groups for mean $\mathrm{DM}_{\mathrm{H}}$, with the deviation being $0.0985 \mathrm{~mm}$ in CBCT group and $0.565 \mathrm{~mm}$ in RVG group. Mini-implants were placed at a lower height (closer to the arch wire) in the RVG group. The differences in the mean values for $\mathrm{DM}_{\mathrm{EP}}$, $\mathrm{DM}_{\mathrm{T}}$, and $\mathrm{DM}_{\mathrm{A}}$ were statistically non-significant.

Intragroup comparisons are depicted in Tables 2 and 3. No statistically significant difference was observed on the right and left side and in the maxillary and mandibular arches in each of the groups.

Table 2 Comparison of mean deviation of mini-implants from ideal position between right and left side in CBCT group and RVG group with level of significance

\begin{tabular}{|c|c|c|c|c|c|c|}
\hline \multirow[t]{2}{*}{ Variable } & \multicolumn{3}{|c|}{$\mathrm{CBCT}$ group } & \multicolumn{3}{|l|}{ RVG group } \\
\hline & $\begin{array}{l}\text { Right side } \\
(n=10)\end{array}$ & $\begin{array}{l}\text { Left side } \\
(n=10)\end{array}$ & $\begin{array}{l}\text { Significance } \\
\text { ( } p \text { value) }\end{array}$ & $\begin{array}{l}\text { Right side } \\
(n=10)\end{array}$ & $\begin{array}{l}\text { Left side } \\
(n=10)\end{array}$ & $\begin{array}{l}\text { Significance } \\
(p \text { value) }\end{array}$ \\
\hline Mean $\mathrm{DM}_{\mathrm{H}}$ (in mm) & 0.091 & 0.106 & 0.939 & 0.768 & 0.362 & 0.226 \\
\hline Mean $\mathrm{DM}_{\mathrm{EP}}$ (in mm) & 0.361 & 0.422 & 0.662 & 0.57 & 0.733 & 0.702 \\
\hline Mean $\mathrm{DM}_{\mathrm{T}}$ (in mm) & 0.756 & 0.079 & 0.256 & 0.815 & 1.261 & 0.111 \\
\hline Mean $\mathrm{DM}_{\mathrm{A}}$ (in degrees) & 4.6 & 0.2 & 0.873 & 2.8 & 5.6 & 0.563 \\
\hline
\end{tabular}

$\mathrm{DM}_{\mathrm{H}}$, deviation of height of mini-implant; $\mathrm{DM}_{\mathrm{EP}}$, deviation of point of entry of mini-implant; $\mathrm{DM}_{\mathrm{T}}$, deviation of tip of mini-implant; $\mathrm{DM} \mathrm{A}_{\mathrm{A}}$ angular deviation of mini-implant from the ideal path. 
Table 3 Comparison of mean deviation of mini-implants from ideal position between maxillary and mandibular sites in the CBCT group and RVG group, respectively, with level of significance

\begin{tabular}{|c|c|c|c|c|c|c|}
\hline \multirow[t]{2}{*}{ Variable } & \multicolumn{3}{|l|}{ CBCT group } & \multicolumn{3}{|l|}{ RVG group } \\
\hline & $\begin{array}{l}\text { Maxillary site } \\
(n=12)\end{array}$ & $\begin{array}{l}\text { Mandibular site } \\
(n=8)\end{array}$ & $\begin{array}{l}\text { Significance } \\
\text { ( } p \text { value) }\end{array}$ & $\begin{array}{l}\text { Maxillary site } \\
(n=12)\end{array}$ & $\begin{array}{l}\text { Mandibular site } \\
(n=8)\end{array}$ & $\begin{array}{l}\text { Significance } \\
\text { ( } p \text { value) }\end{array}$ \\
\hline Mean $\mathrm{DM}_{\mathrm{H}}$ (in mm) & 0.0825 & 0.1225 & 0.256 & 0.65 & 0.436 & 0.354 \\
\hline Mean $\mathrm{DM}_{\mathrm{EP}}$ (in mm) & 0.361 & 0.436 & 0.570 & 0.505 & 0.871 & 0.149 \\
\hline Mean $\mathrm{DM}_{\mathrm{T}}$ (in mm) & 0.499 & 0.717 & 0.401 & 0.944 & 1.178 & 0.727 \\
\hline Mean $\mathrm{DM}_{\mathrm{A}}$ (in degrees) & 4.416 & 5.125 & 0.683 & 4 & 9.5 & 0.099 \\
\hline
\end{tabular}

$\mathrm{DM}_{\mathrm{H}}$, deviation of height of mini-implant; $\mathrm{DM}_{\mathrm{EP}}$, deviation of point of entry of mini-implant; $\mathrm{DM}_{\mathrm{T}}$, deviation of tip of mini-implant; $\mathrm{DM} \mathrm{A}_{\mathrm{r}}$ angular deviation of mini-implant from the ideal path.

In this study, three out of twenty mini-implants in the RVG group showed root contact. Of the three root contacts, one showed proximity to the second premolar and two showed proximity to the first molar. All the three miniimplants which contacted the root surface were placed in the mandibular arch and none of them showed any signs of failure during the loading period of 2 months.

One mini-implant in the RVG group was removed within the first week of loading due to increased mobility and, hence, was considered a failure. This failed mini-implant was not in contact with any of the neighboring roots.

\section{Discussion}

The importance of accurate mini-implant positioning cannot be overemphasized. Accurate mini-implant positioning reduces problems such as loosening of the implant or invasion of the sinuses, periodontal ligament, or root surface and facilitates the use of proper force vectors during loading [22].

In this study, CBCT scan, to assess the possible sites for mini-implant placement, was done after preparatory orthodontic treatment unlike other studies [9-12] where CBCT scan was done prior to the treatment. Since the CBCT scan was not routinely done for all the patients for orthodontic diagnosis, hence, only after a confirmatory diagnosis patients were included in the study and exposed to CBCT. Secondly, any change in the root position and crown inclination during preparatory orthodontic treatment may interfere with the mini-implant positioning according to pretreatment $\mathrm{CBCT}$. Also, taking $\mathrm{CBCT}$ after preparatory orthodontic treatment allowed the use of orthodontic arch wire as a standard reference line. Measurements done in relation to this standard reference can be used clinically without the need of expensive surgical guides/templates. Alveolar crest and cemento-enamel junction were not used as reference because these could not be seen and correlated clinically.

In the present study, the mini-implants in the RVG group were placed at a relatively lower height (i.e., closer to the arch wire) as compared to the ideal height determined, the mean (average) deviation being $0.565 \mathrm{~mm}$. Considering the general guidelines for optimal sites for mini-implant placement as quoted by Fayed et al. [8] and Poggio et al [23] in which a range of different heights are given for mini-implant positioning, clinical relevance of the difference in height of mini-implants in this study is questionable. Considering the mean deviations in the mesiodistal direction namely the mean $\mathrm{DM}_{\mathrm{EB}} \mathrm{DM}_{\mathrm{T}}$, and $\mathrm{DM}_{\mathrm{A}}$, results showed a higher deviation in the RVG group, but the difference in the two groups was not statistically significant. And most of the mini-implants in both the groups were placed within the safe zone in the interradicular space.

Root contact was defined as the contact of mini-implant surface with the neighboring root in the CBCT images. Three out of twenty mini-implants in the RVG group showed root contact while others followed a path with varying amounts of linear and angular deviation from the ideal path without contacting the root surface. According to a study by Lee et al. [24], peri-root space might not be an absolute parameter for mini-implant stability as movement of about $0.5 \mathrm{~mm}$ was detected even in stable miniimplants under loading $[25,26]$. Fortunately, it is not necessarily detrimental even if the root is touched by the screw because almost complete root repair has been reported from an animal study [27]. The biologic nature and the osteodynamics around the orthodontic miniscrew under constant load need to be elucidated further in the future.

It is found that $15 \%$ of the mini-implants placed in the RVG group had root contact while none in the CBCT group had root contact. On careful evaluation of the postplacement $\mathrm{CBCT}$, it was found that all the three mini-implants in the RVG group which contacted the root surface were placed in the mandibular interradicular space. The root contact may have occurred due to the presence of narrower interradicular spaces in the mandibular arches and reduced accessibility in the mandibular posterior region $[8,23]$.

One mini-implant in the RVG group, which was removed within the first week of loading, was not in contact with any of the neighboring roots but was placed relatively closer to the arch wire. On retrospective evaluation, it was concluded that the reason for the failure of the mini-implant could be insufficient cortical bone thickness at the site of 
mini-implant placement which is thought to be a key determinant for initial stability of mini-implant [28-30].

The present study indicated no significant difference in deviation from the ideal placement of mini-implants between the right and left sides and between the maxillary and mandibular sites in each of the two groups. This shows that the operator was not biased towards any site during the mini-implant placement procedure.

From the above discussion, it can be stated that none of the two methods were able to guide the mini-implant accurately at the ideal position. However, most of the mini-implants in both the groups were placed in a safe zone without damaging the adjacent roots.

Fabrication of surgical stents, guides, and templates [9-12] is complicated, time-consuming, expensive, and required massive laboratory equipments and, hence, use of any of these latest technological advances for threedimensional planning, and placement of mini-implants in the $\mathrm{CBCT}$ group was not considered.

Most clinicians use IOPA view of the region with a surgical guide in place to identify the site for mini-implant insertion. Hence, we used a grid in the RVG group in order to simulate the routine protocol used by most of the clinicians. However, no guide was used during insertion of the mini-implants. From the observations of our study, it can be concluded that the use of two-dimensional radiographs with a surgical guide is a more practical and costeffective alternative to the three-dimensional planning with $\mathrm{CBCT}$ for routine mini-implant placement.

\section{Conclusions}

The following can be concluded from this study.

- Although CBCT provides accurate threedimensional visualization of the interradicular space, two-dimensional intraoral radiographs seem to provide sufficient information for mini-implant placement.

- It is recommended for clinicians to use two-dimensional radiographs with surgical guide for routine mini-implant placement.

- Considering the high cost and higher radiation dose as compared to two-dimensional radiographs, the routine use of $\mathrm{CBCT}$ is not recommended for orthodontic mini-implant placement. However, if mini-implant placement is difficult because of complex anatomy such as an expanded sinus or alveolar bone loss, the use of $\mathrm{CBCT}$ data for planning may be considered.

\footnotetext{
Abbreviations

CBCT: Cone beam computed tomography; $\mathrm{DM}_{\mathrm{A}}$ : Angular deviation of the mini-implant from the ideal path; $\mathrm{DM}_{\mathrm{EP}}$ : Deviation of the point of entry of mini-implant; $\mathrm{DM}_{\mathrm{H}}$ : Deviation of height of mini-implant from the ideal height; DMT: Deviation of the tip of mini-implant; RVG: Radiovisiography.
}

Competing interests

The authors declare that they have no competing interests.

\section{Authors' contributions}

The work presented here was carried out in collaboration with all the authors. SK, TT, PR, and AK defined the research theme and designed the study. SK conducted the study, performed the literature review, interpreted the results, and wrote the manuscript. $\Pi$ was the chief supervisor of the study and provided guidance in every phase of the study and the writing of the manuscript. PR guided in statistical analysis, interpretation of data, and discussion of the study. AK guided in the statistical analysis and interpretation of data. All authors read and approved the final manuscript.

Received: 9 June 2014 Accepted: 24 October 2014

Published online: 18 November 2014

\section{References}

1. Buschang PH, Carrillo R, Ozenbaugh B, Rossouw PE. 2008 survey of AAO members on miniscrew usage. J Clin Orthod. 2008; 42(9):513-8.

2. Markic G, Katsaros C, Pandis N, Eliades T. Temporary anchorage device usage: a survey among Swiss orthodontists. Prog Orthod. 2014; 15(1):29.

3. Park J, Cho HJ. Three-dimensional evaluation of interradicular spaces and cortical bone thickness for the placement and initial stability of microimplants in adults. Am J Orthod Dentofacial Orthop. 2009; 136:314. e1-e12.

4. Cheng SJ, Tseng IY, Lee JJ, Kok SH. A prospective study of the risk factors associated with failure of mini-implants used for orthodontic anchorage. Int J Oral Maxillofac Implants. 2004; 19:100-6.

5. Tseng YC, Hsieh CH, Chen CH, Shen YS, Huang IY, Chen CM. The application of mini-implants for orthodontic anchorage. Int J Oral Maxillofac Surg. 2006; 35:704-7.

6. Kravitz ND, Kusnoto B. Risks and complications of orthodontic miniscrews. Am J Orthod Dentofacial Orthop. 2007; 131:S43-51.

7. Chugh T, Ganeshkar SV, Revankar AV, Jain AK. Quantitative assessment of interradicular bone density in the maxilla and mandible: implications in clinical orthodontics. Prog Orthod. 2013; 14(1):38.

8. Fayed MM, Pazera P, Katsaros C. Optimal sites for orthodontic mini-implant placement assessed by cone beam computed tomography. Angle Orthod. 2010; 80:939-51.

9. Kim SH, Choi YS, Hwang EH, Chung KR, Kook YA, Nelson G. Surgical positioning of orthodontic mini-implants with guides fabricated on models replicated with cone-beam computed tomography. Am J Orthod Dentofacial Orthop. 2007; 131(4):S82-9.

10. Liu H, Liu D, Wang G, Wang CH, Zhao Z. Accuracy of surgical positioning of orthodontic miniscrews with a computer-aided design and manufacturing template. Am J Orthod Dentofacial Orthop. 2010; 137(6):728. e1-e10.

11. Morea C, Dominguez GC, Wuo Ado V, Tortamano A. Surgical guide for optimal positioning of mini-implants. J Clin Orthod. 2005; 39:317-21.

12. Kim SH, Kang JM, Choi B, Nelson G. Clinical application of a stereolithographic surgical guide for simple positioning of orthodontic mini-implants. World J Orthod. 2008; 9:371-82.

13. Grunheid T, Schieck JRK, Pliska BT, Ahmad M, Larson BE. Dosimetry of a cone-beam computed tomography machine compared with a digital x-ray machine in orthodontic imaging. Am J Orthod Dentofacial Orthop. 2012; 141:436-43.

14. Kuijpers-Jagtman AM, Kuijpers MAR, Schols JGJ, Maal TJJ, Breuning KIH, Van Vlijmen OJC. The use of cone-beam computed tomography for orthodontic purposes. Semin Orthod. 2013; 19:196-203.

15. Pauwels R, Beinsberger J, Collaert B, Theodorakou C, Rogers J, Walker A, Cockmartin L, Bosmans H, Jacobs R, Bogaerts R, Horner K. Effective dose range for dental cone beam computed tomography scanners. Eur $J$ Radiol. 2012; 81(2):267-71.

16. Estelita S, Janson G, Chiqueto K, Janson M, de Freitas MR. Predictable drill-free screw positioning with a graduated 3-dimensional radiographic-surgical guide: a preliminary report. Am J Orthod Dentofacial Orthop. 2009; 136:722-35.

17. Suzuki EY, Buranastidporn B. An adjustable surgical guide for miniscrew placement. J Clin Orthod. 2005; 39:588-90.

18. Pithon MM, dos Santos RL. Fabrication of an adjustable miniscrew surgical guide. J Orthod. 2010; 37:118-20. 
19. Kalra S, Tripathi T, Rai P, Kanase A. A simple and versatile mini-implant guide. J Clin Orthod. 2014; 48(4):248.

20. Felicita SA. A simple three-dimensional stent for proper placement of mini-implant. Prog Orthod. 2013; 14(1):45.

21. Rai $P$, Tripathi T. A versatile grid holder and grid for miniscrew placement. Int J Orthod. 2011; 22(1):43-5.

22. Kim SH, Kang SM, Choi YS, Kook YA, Chung KR, Huang JC. Cone-beam computed tomography evaluation of mini-implants after placement: is root proximity a major risk factor for failure? Am J Orthod Dentofacial Orthop. 2010; 138:264-76.

23. Poggio PM, Incorvati C, Velo S, Carano A. "Safe zones": a guide for miniscrew positioning in the maxillary and mandibular arch. Angle Orthod. 2006; 76:191-7.

24. Lee KJ, Joo E, Kim KD, Lee JS, Park YC, Yu HS. Computed tomographic analysis of tooth-bearing alveolar bone for orthodontic miniscrew placement. Am J Orthod Dentofacial Orthop. 2009; 135:486-94.

25. Ohmae M, Saito S, Morohashi T, Seki K, Qu H, Kanomi R, Yamasaki Kl, Okano T, Yamada S, Shibasaki Y. A clinical and histological evaluation of titanium mini-implants as anchors for orthodontic intrusion in the beagle dog. Am J Orthod Dentofacial Orthop. 2001; 119:489-97.

26. Liou EJ, Pai BC, Lin JC. Do miniscrews remain stationary under orthodontic forces? Am J Orthod Dentofacial Orthop. 2004; 126:42-7.

27. Asscherickx K, Vannet BV, Wehrbein H, Sabzevar MM. Root repair after injury from mini-screw. Clin Oral Implants Res. 2005; 16:575-8.

28. Frost HM. Wolff's law and bone's structural adaptations to mechanical usage: an overview for clinicians. Angle Orthod. 1994; 64:175-88.

29. Dalstra M, Cattaneo PM, Melsen B. Load transfer of miniscrews for orthodontic anchorage. J Orthod. 2004; 1:53-62.

30. Moon CH, Lee DG, Lee HS, Im JS, Baek SH. Factors associated with the success rate of orthodontic miniscrews placed in the upper and lower posterior buccal region. Angle Orthod. 2008; 78:101-6.

doi:10.1186/s40510-014-0061-x

Cite this article as: Kalra et al.: Evaluation of orthodontic mini-implant placement: a CBCT study. Progress in Orthodontics 2014 15:61.

\section{Submit your manuscript to a SpringerOpen ${ }^{\circ}$ journal and benefit from:}

- Convenient online submission

- Rigorous peer review

- Immediate publication on acceptance

- Open access: articles freely available online

- High visibility within the field

- Retaining the copyright to your article

Submit your next manuscript at $\gg$ springeropen.com 